\title{
Antibodies to citrullinated peptides are not associated with the rate of joint destruction in patients with a well-established diagnosis of rheumatoid arthritis
}

\author{
A.M. Nieto-Colonia1, W.S. Santos ${ }^{3}$, S.P. Keusseyan ${ }^{1}$, W. Caldana², A.R.C. Fernandes ${ }^{2}$ \\ and L.E.C. Andrade ${ }^{1}$ \\ 1Disciplina de Reumatologia, ${ }^{2}$ Departamento de Imagem, Escola Paulista de Medicina, Universidade \\ Federal de São Paulo, São Paulo, SP, Brasil \\ ${ }^{3}$ Faculdade de Medicina, Escola Superior de Ciências da Saúde, Brasília, DF, Brasil \\ Correspondence to: L.E.C. Andrade, Disciplina de Reumatologia, UNIFESP, Rua Botucatu, 740, \\ 04023-062 São Paulo, SP, Brasil \\ Fax: +55-11-5579-6665. E-mail: luis@reumato.epm.br
}

\begin{abstract}
Antibodies to citrullinated peptides are highly specific for rheumatoid arthritis (RA) and represent a significant risk factor for undifferentiated polyarthritis. This prognostic ability may be related to the very diagnostic performance of these autoantibodies, since RA is a more erosive disease than other forms of arthritis. The present study evaluated an association of antibodies to citrullinated peptides and the rate of joint destruction in patients with a well-established diagnosis of RA. Seventy-one patients with RA were evaluated in 1994 and again in 2002 (functional class, joint count, Health Assessment Questionnaire score, hands X-ray). Autoantibodies (rheumatoid factor (RF), anti-perinuclear factor, anti-cyclic citrullinated peptide (CCP) antibodies) and Sharp's index were analyzed blindly. Delta Sharp was calculated as the difference in Sharp's index obtained in 1994 and 2002. During the follow-up the Health Assessment Questionnaire score increased from $0.91 \pm 0.74$ to $1.39 \pm 0.72$ ( $P<0.001)$. Similarly, the number of swollen joints increased from $4.6 \pm 5.71$ to $6.4 \pm 4.1(P=0.002)$. The frequency of autoantibodies and anti-CCP titer remained stable; however, serum RF concentration increased from $202.8 \pm 357.6$ to $416.6 \pm 636.5 \mathrm{IU} / \mathrm{mL}(\mathrm{P}=0.003)$. Sharp's index increased from $56.7 \pm 62.1$ to $92.4 \pm 80.9(P<0.001)$. No correlation was observed between Delta Sharp and the presence of RF, anti-perinuclear factor, and anti-CCP antibodies at baseline. Antibodies to citrullinated epitopes are specific and early markers for the diagnosis of RA but do not seem to be associated with the rate of joint destruction in patients with a wellestablished diagnosis of RA.
\end{abstract}

Key words: Rheumatoid arthritis; Rheumatoid factor; Autoantibodies; Citrullinated peptides; Disease severity; Joint imaging

Research supported by CNPq and by the Brazilian Society of Rheumatology.

Publication supported by FAPESP.

Received May 14, 2007. Accepted December 3, 2007

\section{Introduction}

The last decade has brought two important breakthroughs for the management and understanding of rheumatoid arthritis (RA). Heralded by monoclonal antibodies to TNF- $\alpha$, the class of biological therapeutic agents has been shown to be able to favorably interfere with the natural history of RA to an extent never achieved before, especially when administered early in the course of the disease (1). In the second half of the 1990's, two systems of autoantibodies previously known to be associated with RA (anti-perinuclear factor (APF) and anti-keratin antibodies) were shown to be part of the highly specific system of antibodies to citrullinated epitopes $(2,3)$. The last few 
years have provided plenty of evidence for the high diagnostic performance of the antibodies to citrullinated epitopes in early stages of RA (4-6). This is particularly relevant since a definite diagnosis of $R A$ is based on clinical and radiographic criteria that usually are present when some degree of irreversible structural damage to the joints has already occurred. In this regard, it is noteworthy that antibodies to citrullinated peptides have high positive predictive value for identifying patients who will develop definite RA among those with early undifferentiated polyarthritis (7).

However, once the diagnosis of RA is met there is still one point to be defined. How erosive and incapacitating is it going to be? The broad spectrum of severity of RA ranges from a mild disease with low incapacity potential to highly erosive and incapacitating forms $(8,9)$. The knowledge of the erosive potential of RA in a particular patient is relevant to the therapeutic planning. Several elements have been suggested as predictors of outcome, such as early erosive disease, high erythrocyte sedimentation rate and serum levels of $\mathrm{C}$-reactive protein at the onset of the disease, the presence of rheumatoid factor, and the presence of the shared DRB1 epitope (reviewed in Ref. 10).

Recent studies have demonstrated that antibodies to citrullinated epitopes are quite efficient in predicting the development of epiphysis erosions among patients with early undifferentiated polyarthritis $(7,11-13)$. This discriminative ability may be related to the diagnostic property of antibodies to citrullinated epitopes of differentiating patients with RA, an erosive disease, from patients with other forms of polyarthritis with a benign course. However, it has not been firmly established if this class of autoantibodies can predict the erosive potential among patients with a well-established diagnosis of RA. In the present study, we evaluated the joint destruction rate in a series of patients with well-defined RA along a 9-year interval according to the presence of antibodies to citrullinated epitopes and rheumatoid factor.

\section{Patients and Methods}

A series of 176 patients with RA according to the American College of Rheumatology classification criteria (14) recruited by convenience was characterized in 1994 in a tertiary university medical school (UNIFESP, São Paulo, SP, Brazil) $(15,16)$. Serum samples obtained in 1994 were stored at $-80^{\circ} \mathrm{C}$. In 2002 , extensive efforts led to the retrieval of 71 patients from this original series. After informed consent, all 71 patients underwent blood sampling, hand radiographs (baseline foot radiographs were not available for several patients), and the standard clinical protocol used in 1994.
Serum samples were kept at $-80^{\circ} \mathrm{C}$ until use. Radiographs obtained in 1994 and in 2002 were scored side by side for Sharp's index (17) by two experienced radiologists who were unaware of the clinical and laboratory variables. The difference in Sharp's index obtained in 2002 and 1994 for each patient was designated as Delta Sharp. The standard evaluation protocol comprised clinical history, physical examination, duration of morning stiffness, number of swollen joints, presence of extra-articular manifestations, and application of the Health Assessment Questionnaire (HAQ) (18). Physicians in charge of the clinical evaluation were blind to the autoantibody status. The therapeutic regimen of the cohort was rather homogeneous, comprising chloroquine diphosphate and methotrexate plus non-steroidal anti-inflammatory drugs and/or low-dose oral prednisone (not exceeding $15 \mathrm{mg} /$ day). No patient received immunosuppressive or biological therapy.

Laboratory tests included erythrocyte sedimentation rate and autoantibody determination. Rheumatoid factor was determined by the standard latex agglutination technique (Dade Behring, Marburg, Germany). APF was determined by indirect immunofluorescence in buccal mucosa cells from a single "positive" donor according to the standard technique (19). Anti-cyclic citrullinated peptide (CCP) antibodies were determined by ELISA (Shield-axis, England) according to manufacturer instructions, with a cut-off of $20 \mathrm{AU} / \mathrm{mL}$. Samples from 1994 and 2002 were processed in parallel.

Contingency tables for qualitative variables were evaluated by the chi-square test or Fisher's exact test when appropriate. Quantitative variables in two non-paired groups were compared by the Mann-Whitney test. For dependent groups, the Wilcoxon test was applied. Correlation between quantitative variables was estimated by the Pearson correlation coefficient. $\mathrm{P}$ values less than 0.05 were considered significant.

\section{Results}

Of the 176 patients originally enrolled in the study in 1994 we were able to contact 71 patients (59 women and 12 men) in 2002. At the beginning of follow-up (1994) the age of these 71 patients ranged from 21 to 77 years (mean \pm SD: $46.7 \pm 11.5$ years). The series comprised patients over a large span of disease duration $(8.9 \pm 6.7$ years, ranging from 0 to 25 years). Four patients had less than 2 years of disease, 25 had more than 2 and less than 5 years of disease duration, 19 had more than 5 and less than 10 years of disease duration, and 23 patients had more than 10 years of disease duration.

Along the 9-year interval, the HAQ score increased 
from $0.91 \pm 0.74$ (ranging from 0 to 2.38 ) at baseline in 1994 to $1.39 \pm 0.72$ (ranging from 0.13 to 2.88 ) in 2002 . The increase in $\mathrm{HAQ}$ score was statistically significant $(\mathrm{P}<$ 0.001 ). Accordingly, the number of swollen joints increased from $4.6 \pm 5.71$ (median 3) in 1994 to $6.4 \pm 4.1$ (median 6) in $2002(P=0.002)$. On the other hand, the duration of morning stiffness decreased from $58 \pm 72$ min (median 20) in 1994 to $31.8 \pm 26.3$ min (median 30$)$ in $2002(P=0.03)$.

Rheumatoid factor above $80 \mathrm{IU} / \mathrm{mL}$ was observed in 48 patients $(67.6 \%)$ in 1994 and in 46 patients $(64.7 \%)$ in 2002. There was a significant increase in the serum concentration of rheumatoid factor in the 9-year interval (Table 1). APF was detected in 48 patients (67.6\%) in 1994 and in 46 patients $(64.8 \%)$ in 2002 , with no significant variation in titer (Table 1). Anti-CCP antibodies were present in 51 patients $(71.8 \%)$ in 1994 and in 48 patients (67.6\%) patients in 2002 , with no significant variation in serum concentration for the group as a whole (Table 1). However, there was some variation in titer for some patients although no relationship to clinical features or therapeutic interventions could be clearly identified (data not shown).

Along the 9-year interval there was a significant increase in joint destruction as measured by Sharp's index (12 \pm 18.2 ; Table 1$)$. The rate of joint destruction, as judged by Delta Sharp, did not differ significantly according to the presence of rheumatoid factor, APF, and anti-CCP antibodies (Table 2 and Figure 1). As can be observed in Figure 1, the majority of patients with Delta Sharp above 20 presented a positive reaction for rheumatoid factor (75\%), APF (69\%), and anti-CCP antibodies (81\%). However, this was not statistically different from the number of patients with Delta Sharp under 20 presenting a positive reaction for rheumatoid factor $(65 \%)$, APF (62\%), and anti-CCP antibodies (69\%).

\section{Discussion}

The present study analyzed the clinical, radiographic, and immunologic features of a series of $71 \mathrm{RA}$ patients along a 9-year interval. As a group, there was progressive deterioration in functional capacity and in joint structure. The serum levels of APF and anti-CCP antibodies tended to remain stable while serum levels of rheumatoid factor increased along the 9-year interval. There was no consistent association of autoantibody status at baseline with rate of joint destruction along the 9-year interval. in 2002.
The outcome measure for evaluation of disease severity was the rate of joint destruction as measured by the progression in Sharp index. Therefore, we calculated the difference in Sharp index between the end and the beginning of the study for each patient and tested the correlation of this parameter with the autoantibody status at the beginning of the study. No statistically significant correlation between the baseline autoantibody status and the rate of joint destruction was observed. When a subgroup of patients with a noticeably higher rate of joint destruction was compared to the rest of the patients there was a slight overrepresentation of positive reactions for the three autoantibodies but with no statistical significance. It could be argued that the ability to assess the rate of joint destruction might be hampered in a sample of patients with longstanding RA since a fraction of patients display more

Table 1. Characterization of 71 patients with rheumatoid arthritis in 1994 and

\begin{tabular}{lcc}
\hline Parameter & Year 1994 & Year 2002 \\
\hline HAQ score & $0.91 \pm 0.74$ & $1.39 \pm 0.72^{*}$ \\
Number of swollen joints & $4.6 \pm 5.71$ & $6.4 \pm 4.1^{*}$ \\
Morning stiffness (min) & $58 \pm 72$ & $31.8 \pm 26.3^{*}$ \\
Extra-articular manifestations & 41 patients $(58 \%)$ & 44 patients $(62 \%)$ \\
ESR (mm/1st hour) & $31.2 \pm 22.3$ & $28.6 \pm 21.5$ \\
Rheumatoid factor $(\mathrm{IU} / \mathrm{mL})$ & $202.8 \pm 357.6$ & $416.6 \pm 636.5^{*}$ \\
APF (titer) & Median $=1 / 10$ & Median $=1 / 10$ \\
& (negative to $1 / 1280)$ & (negative to $1 / 640)$ \\
Anti-CCP $(\mathrm{AU} / \mathrm{mL})$ & $64.8 \pm 48.8$ & $58.9 \pm 57.9$ \\
Sharp's index & $56.7 \pm 62.1$ & $92.4 \pm 80.9^{*}$ \\
\hline
\end{tabular}

Data are reported as means $\pm S D$, unless otherwise indicated. $H A Q=$ Health Assessment Questionnaire; ESR = erythrocyte sedimentation rate: APF = anti-perinuclear factor; anti-CCP = anti-cyclic citrullinated peptide antibodies. ${ }^{*} \mathrm{P}<0.05$ compared to 1994 (Wilcoxon test).

Table 2. Difference in Sharp's index (Delta Sharp) along a 9-year interval according to the autoantibody status in 1994.

\begin{tabular}{lcc}
\hline & \multicolumn{2}{c}{ Autoantibody status in 1994} \\
\cline { 2 - 3 } & Autoantibody present & Autoantibody absent \\
\hline Rheumatoid factor & $\mathrm{N}=49$ & $\mathrm{~N}=22$ \\
& $13.79 \pm 17.53(9.56)$ & $7.99 \pm 19.29(1.42)$ \\
APF & $\mathrm{N}=48$ & $\mathrm{~N}=23$ \\
& $12.43 \pm 17.5(7.80)$ & $11.01 \pm 19.83(2.55)$ \\
Anti-CCP & $\mathrm{N}=50$ & $\mathrm{~N}=21$ \\
& $13.18 \pm 17.59(7.65)$ & $8.89 \pm 19.65(2.23)$ \\
\hline
\end{tabular}

Data are reported as means \pm SD and median in parentheses. APF $=$ antiperinuclear factor; anti-CCP $=$ anti-cyclic citrullinated peptide antibodies. There were no statistical differences in antibody status (Wilcoxon test). 
prominent joint destruction within the first 2 years of disease. However, a substantial portion of patients exhibit a sustained rate of joint destruction along several years $(20,21)$. In fact, the very purpose of the present study was to assess the additional prognostic value of the autoantibodies in patients with a well-established diagnosis of RA and for this purpose the selected sample seemed to be the most appropriate. In addition, an expressive progression in Delta Sharp for the whole group of patients was observed along the 9-year interval and that should be enough to reveal a putative relevant prognostic effect for the autoantibodies.

There are several studies in the literature dealing with the prognostic significance of rheumatoid factor and antibodies to citrullinated epitopes. Some of them detected no prognostic properties for antibodies to citrullinated epitopes $(5,22,23)$. On the other hand, most studies did observe an association of erosive disease with antibodies to citrullinated epitopes and/or rheumatoid factor $(6,7,11$ 13,24-26). Possible reasons for the discrepancy observed in the literature include ethnic differences, distinct criteria for patient selection, diverse methodological protocols, and the presence of confounding variables such as therapeutic interventions. The apparent discrepancy between the present findings and those of some previous studies is probably due to patient selection. Most of the literature studies included only patients with undifferentiated polyarthritis at baseline $(8,12)$ or only patients with very early $R A$ (22-26). It is expected that part of these patients eventually will present definite RA and part of them will turn out to have some other benign form of chronic polyarthritis. There- fore, it is possible that at least part of the previously published association between antibodies to citrullinated epitopes and erosive features is actually due to the high specificity of this system of autoantibodies for the diagnosis of RA. In fact, the present and previous studies with patients with RA of longer duration $(6,20)$ could not detect a prognostic role for these autoantibodies.

The high rate of dropouts in the follow-up (starting with 176 and ending with 71 patients) and the poor clinical and radiographic outcome of this series were probably related to the specific characteristics of the population treated at our service. The low income and social instability of this particular population probably causes many of the patients to move frequently to other regions of the city or of the country. In fact, this same trend has been observed in other outpatient clinics in several public hospitals in large cities in Brazil. The low income also prevents access to consistent therapy and is associated with low educational level. Taken together, these factors are believed to hamper the efficiency of clinical treatment, a fact that may partially explain the poor clinical and radiographic outcome observed here.

It was remarkable that the serum levels of rheumatoid factor increased along the 9-year interval while the serum levels of APF and anti-CCP antibodies remained largely unchanged. This observation probably reflects the uncontrolled clinical course of the disease in this series since it is known that rheumatoid factor levels tend to decrease when the disease moves towards remission (27).

Our data provide no evidence for rheumatoid factor
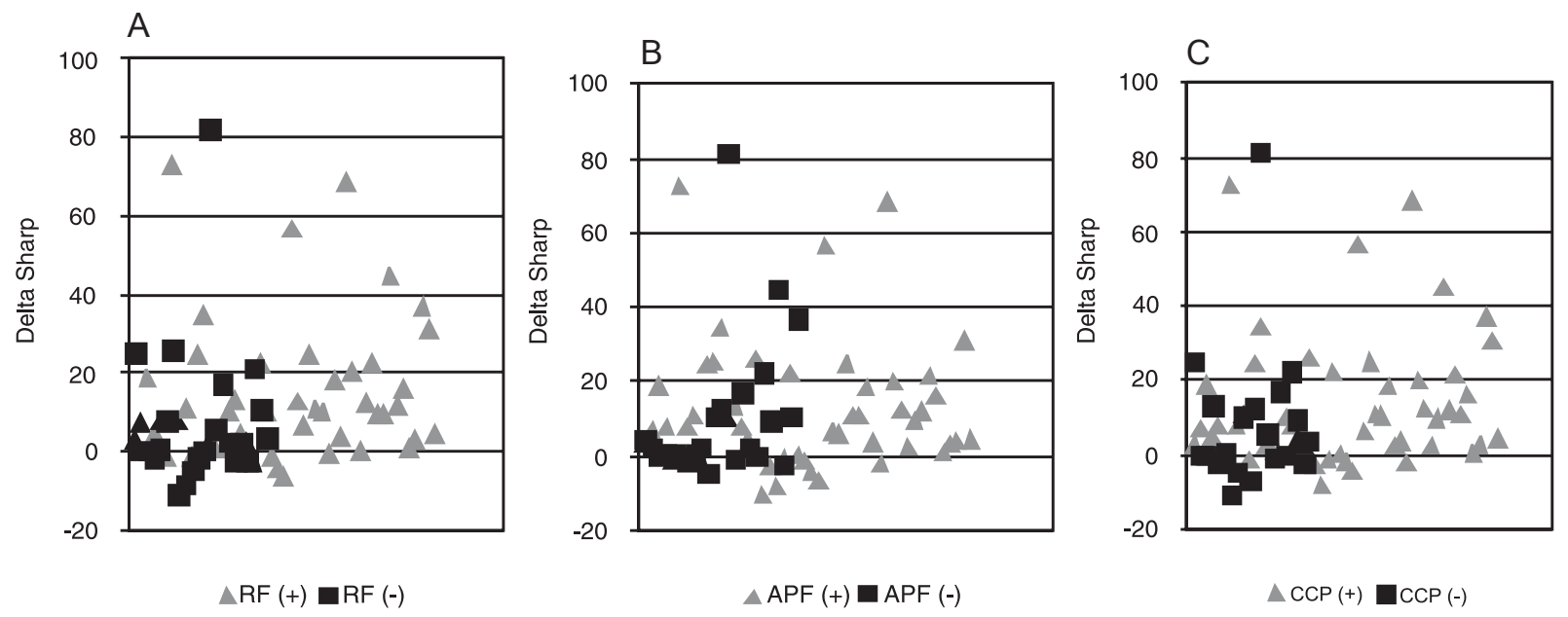

Figure 1. Distribution of the 71 patients with rheumatoid arthritis according to the Delta Sharp (Sharp's index in 2002 minus Sharp's index in 1994) and the presence of rheumatoid factor (RF) (A), anti-perinuclear factor (APF) (B), and anti-cyclic citrullinated peptide $(C C P)$ antibodies $(C)$. Gray triangles represent patients positive for the autoantibody and black squares represent patients negative for the autoantibody. There was no significant difference in Delta Sharp according to the presence of the three autoantibodies (Wilcoxon test). 
and antibodies to citrullinated epitopes having a role for prognostic decisions on an individual basis in patients with a well-established diagnosis of rheumatoid arthritis. This conclusion may not be pertinent to patients with very early rheumatoid arthritis or to patients first seen as a mild form of the disease. At the clinical setting, the novel system of autoantibodies to citrullinated peptides should be faced as RA-specific immunologic markers, especially useful in assisting the diagnosis and prognosis in the context of recent onset polyarthritis.

\section{References}

1. Wolfe AM. The epidemiology of rheumatoid arthritis: a review. I. Surveys. Bull Rheum Dis 1968; 19: 518-523.

2. Taylor PC, Williams RO, Maini RN. Immunotherapy for rheumatoid arthritis. Curr Opin Immunol 2001; 13: 611-616.

3. Schellekens GA, de Jong BA, van den Hoogen FH, van de Putte LB, van Venrooij WJ. Citrulline is an essential constituent of antigenic determinants recognized by rheumatoid arthritis-specific autoantibodies. J Clin Invest 1998; 101: 273281.

4. Girbal-Neuhauser E, Durieux JJ, Arnaud M, Dalbon P, Sebbag M, Vincent C, et al. The epitopes targeted by the rheumatoid arthritis-associated antifilaggrin autoantibodies are posttranslationally generated on various sites of (pro) filaggrin by deimination of arginine residues. J Immunol 1999; 162: $585-594$

5. Schellekens GA, Visser $H$, de Jong BA, van den Hoogen $F H$, Hazes JM, Breedveld FC, et al. The diagnostic properties of rheumatoid arthritis antibodies recognizing a cyclic citrullinated peptide. Arthritis Rheum 2000; 43: 155-163.

6. Kurki P, Aho K, Palosuo T, Heliovaara M. Immunopathology of rheumatoid arthritis. Antikeratin antibodies precede the clinical disease. Arthritis Rheum 1992; 35: 914-917.

7. van Jaarsveld $\mathrm{CH}$, ter Borg $\mathrm{EJ}$, Jacobs JW, Schellekens GA, Gmelig-Meyling FH, van Booma-Frankfort C, et al. The prognostic value of the antiperinuclear factor, anti-citrullinated peptide antibodies and rheumatoid factor in early rheumatoid arthritis. Clin Exp Rheumatol 1999; 17: 689-697.

8. van Gaalen FA, Linn-Rasker SP, van Venrooij WJ, de Jong BA, Breedveld FC, Verweij CL, et al. Autoantibodies to cyclic citrullinated peptides predict progression to rheumatoid arthritis in patients with undifferentiated arthritis: a prospective cohort study. Arthritis Rheum 2004; 50: 709-715.

9. Feigenbaum SL, Masi AT, Kaplan SB. Prognosis in rheumatoid arthritis. A longitudinal study of newly diagnosed younger adult patients. Am J Med 1979; 66: 377-384.

10. Wolfe F, Cathey MA. The assessment and prediction of functional disability in rheumatoid arthritis. I Rheumatol 1991; 18: 1298-1306.

11. Young $A$, van der Heijde DM. Can we predict aggressive disease? Baillieres Clin Rheumatol 1997; 11: 27-48.

12. Machold KP, Stamm TA, Nell VP, Pflugbeil S, Aletaha D, Steiner G, et al. Very recent onset rheumatoid arthritis: clinical and serological patient characteristics associated with radiographic progression over the first years of disease. Rheumatology 2007; 46: 342-349.

13. Berglin E, Johansson T, Sundin U, Jidell E, Wadell G, Hallmans G, et al. Radiological outcome in rheumatoid arthritis is predicted by presence of antibodies against cyclic citrullinated peptide before and at disease onset, and by IgARF at disease onset. Ann Rheum Dis 2006; 65: 453-458.

14. Arnett FC, Edworthy SM, Bloch DA, McShane DJ, Fries JF, Cooper NS, et al. The American Rheumatism Association 1987 revised criteria for the classification of rheumatoid arthritis. Arthritis Rheum 1988; 31: 315-324.

15. Santos WS, Fernandes ARC, Andrade LEC. Clinical significance of antiperinuclear factor (APF) and "anti-keratin antibody" (AKA) in rheumatoid arthritis (RA). Arthritis Rheum 1996; 39: S43 (Abstract).

16. Santos WS, Fernandes ARC, Silva NP, Atra E, Andrade LEC. Clinical significance of antiperinuclear factor (APF) and "anti-keratin antibody" (AKA) in rheumatoid arthritis (RA). Rev Bras Reumatol 1997; 37: 309-316.

17. Sharp JT, Bluhm GB, Brook A, Brower AC, Corbett M, Decker JL, et al. Reproducibility of multiple-observer scoring of radiologic abnormalities in the hands and wrists of patients with rheumatoid arthritis. Arthritis Rheum 1985; 28 : 16-24.

18. Ferraz MB, Oliveira LM, Araujo PM, Atra E, Tugwell P. Crosscultural reliability of the physical ability dimension of the Health Assessment Questionnaire. J Rheumatol 1990; 17: 813-817.

19. Hoet RM, Boerbooms AM, Arends M, Ruiter DJ, van Venrooij WJ. Antiperinuclear factor, a marker autoantibody for rheumatoid arthritis: colocalisation of the perinuclear factor and profilaggrin. Ann Rheum Dis 1991; 50: 611-618.

20. Wolfe F, Sharp JT. Radiographic outcome of recent-onset rheumatoid arthritis: a 19-year study of radiographic progression. Arthritis Rheum 1998; 41: 1571-1582.

21. Graudal NA, Jurik AG, de Carvalho A, Graudal HK. Radiographic progression in rheumatoid arthritis: a long-term prospective study of 109 patients. Arthritis Rheum 1998; 41: $1470-1480$

22. Bas S, Perneger TV, Mikhnevitch E, Seitz M, Tiercy JM, Roux-Lombard $\mathrm{P}$, et al. Association of rheumatoid factors and anti-filaggrin antibodies with severity of erosions in rheumatoid arthritis. Rheumatology 2000; 39: 1082-1088.

23. Vittecoq O, Pouplin S, Krzanowska K, Jouen-Beades F, Menard JF, Gayet A, et al. Rheumatoid factor is the strongest predictor of radiological progression of rheumatoid arthritis in a three-year prospective study in community-recruited patients. Rheumatology 2003; 42: 939-946.

24. Forslin K, Vincent C, Serre G, Svensson B. Antifilaggrin antibodies in early rheumatoid arthritis may predict radiological progression. Scand J Rheumatol 2001; 30: 221-224.

25. Vencovsky J, Machacek S, Sedova L, Kafkova J, Gatterova $\mathrm{J}$, Pesakova V, et al. Autoantibodies can be prognostic markers of an erosive disease in early rheumatoid arthritis. Ann Rheum Dis 2003; 62: 427-430.

26. Meyer O, Labarre C, Dougados M, Goupille P, Cantagrel A, Dubois $A$, et al. Anticitrullinated protein/peptide antibody assays in early rheumatoid arthritis for predicting five year radiographic damage. Ann Rheum Dis 2003; 62: 120-126.

27. Ahmed MM, Mubashir E, Wolf RE, Hayat S, Hall V, Shi R, et al. Impact of treatment with infliximab on anticyclic citrullinated peptide antibody and rheumatoid factor in patients with rheumatoid arthritis. South Med J 2006; 99: 1209-1215. 